DOI: http://dx.doi.org/10.18764/2358-4319.v9n3p218-250.

\title{
POLÍTICAS PÚBLICAS EDUCACIONAIS E ESCOLARIZAÇÃO INDÍGENA
}

\author{
Terezinha do Socorro Lira Pereira' \\ Tania Suely Azevedo Brasileiro ${ }^{2}$
}

\section{RESUMO}

A temática tratada neste artigo se refere a uma breve historiografia sobre as políticas públicas educacionais e o processo de escolarização dos povos indígenas. Faz parte do construto bibliográfico relacionado à pesquisa de mestrado, ainda em andamento, desenvolvida no Programa de Pós-Graduação em Educação da Universidade Federal do Oeste do Pará (PPGE/Ufopa), com o tema "Educação Superior Indígena na Amazônia". O objetivo principal deste estudo é verificar o arcabouço teórico existente a respeito das políticas públicas educacionais, compreender o processo de escolarização dos indígenas e verificar a inserção e a participação dessas populações nessas políticas, inclusive no ensino superior com base na experiência vivenciada pela Universidade Federal do Oeste do Pará (Ufopa). Para sua realização, adotou-se, no primeiro momento, um estudo historiográfico das políticas públicas educacionais, considerando as concepções de Paulilo (2010). Em seguida, verificou-se o processo de escolarização dos indígenas, utilizando como enfoque teórico as concepções de Santos (2011) e Secchi (2007). Por fim, para tratar da presença indígena no ensino superior, referenciou-se nos estudos do Grupo de Estudos Multidisciplinares de Ação Afirmativa (2013) e nos documentos institucionais da Ufopa para ilustrar o cesso e a estatística do quantitativo de estudantes indígenas ingressantes nessa instituição.

1 Mestranda em Educação do Programa de Pós-Graduação em Educação (PPGE/Ufopa). E-mail: socorro.lira.ufopa@gmail.com.

2 Professora associada no Instituto de Ciências da Educação da UFOPA. Coordenadora do PPGE. Doutora em Educação pela Universidad Rovira i Virgili/Espanha. Pós-doutora em Psicologia pelo Instituto de Psicologia da Universidade de São Paulo (USP), com Estágio Pós-Doutoral junto à Catedra Vygotsky da Faculdade de Psicologia da Universidad de La Havana - Cuba. E-mail: brasileirotania@gmail.com 
Os resultados obtidos por meio deste estudo oportunizaram conhecer o percurso histórico das políticas públicas em educação, as interferências sociais, econômicas e políticas por elas sofridas. No que se refere ao acesso dos indígenas ao ensino superior, o estudo revelou os desafios desses povos para ter acesso a esse nível de ensino. No caso específico citado da Ufopa, esse desafio é muito maior em função da expressiva diversidade étnico, cultural e racial existente nessa universidade.

Palavras-chave: Educação. Políticas públicas. Escolarização indígena.

\section{EDUCATIONAL PUBLIC POLICY AND INDIGENOUS SCHOOLING}

\section{ABSTRACT}

The issue addressed in this article refers to a brief history on the educational policies and the process of education of indigenous peoples. It is part of the bibliographic construct related to the master's research, still in progress, developed the Program of Graduate Studies in Education of the Federal University of Western Pará (PPGE/Ufopa), with the theme "Indigenous Higher Education in the Amazon."The aim of this study is to assess the existing theoretical framework regarding public educational policies, understanding of indigenous schooling process and verify the inclusion and participation of these populations in these policies, including higher education based on the experience lived by the Federal University of west of Pará (Ufopa). For its realization, was adopted, at first, a historiographical study of public educational policies, considering the views of Paulilo (2010). Then there was the indigenous schooling, using as theoretical approach the concepts of Santos (2011) and Secchi (2007). Finally, to address the indigenous presence in higher education, it is referenced in studies of the Multidisciplinary Study Group Affirmative Action (2013) and institutional documents Ufopa to illustrate the process and statistics of the quantity of incoming Indian students in that institution. The results obtained through this study oportunizaram us know the historical background of public policies in education, social interference, economic and political they suffered. As regards access 
of indigenous higher education, the study revealed the challenges in these people have to process this level of education. In the case cited, the Ufopa, the challenge is much greater due to the significant ethnic diversity, cultural and racial existing at the university.

Keywords: Education. Public Policies. Education indigenous.

\section{POLÍTICAS PÚBLICAS EDUCATIVAS Y EDUCACIÓN INDÍGENA}

\section{RESUMEN}

El tema abordado en este artículo se refiere a una breve historia de las políticas educativas y el proceso de educación de los pueblos indígenas. Es parte de la construcción bibliográfica relacionada con la investigación de la maestra, aún en curso, desarrollado el Programa de Estudios Graduados en Educación de la Universidad Federal de Pará Occidental (PPGE/Ufopa), con el tema "indígena Educación Superior en la Amazonia." El objetivo de este estudio es evaluar el marco teórico existente en relación con las políticas públicas de educación, la comprensión de proceso de escolarización indígena y verificar la inclusión y la participación de estas poblaciones en estas políticas, incluyendo la educación superior sobre la base de la experiencia vivida por la Universidad Federal de al oeste de Pará (Ufopa). Para su realización, se aprobó, en primer lugar, un estudio historiográfico de las políticas públicas de educación, teniendo en cuenta los puntos de vista de Paulilo (2010). Luego estaba la educación indígena, utilizando como enfoque teórico los conceptos de Santos (2011) y Secchi (2007). Por último, para hacer frente a la presencia indígena en la educación superior, se hace referencia en los estudios de la acción afirmativa Multidisciplinar Grupo de Estudio (2013) y los documentos institucionales Ufopa para ilustrar el proceso y estadísticas de la cantidad de estudiantes de la India entrantes en esa institución. Los resultados obtenidos a través de este estudio oportunizaram nos conocemos los antecedentes históricos de las políticas públicas en educación, la interferencia sociales, económicos y políticos que sufrieron. En cuanto al acceso de la educación superior indígena, el estudio reveló los retos 
de estas personas tienen que procesar este nivel de educación. En el caso citado, el Ufopa, el reto es mucho mayor debido a la considerable diversidad étnica, cultural y racial existente en la universidad.

Palabras clave: Educación. Políticas públicas. Escolarización indígena.

\section{Introdução}

A escolha da temática a ser tratada neste artigo se justifica pela necessidade de compreensão da historiografia das políticas públicas educacionais, bem como da clareza no processo de inserção dos povos indígenas nessas políticas. Os estudos históricos sobre as políticas públicas educacionais no Brasil, as suas regulamentações e a atuação do Estado são questões que serão tratadas ao longo deste texto.

Este tema está no cerne de importantes discussões e abordagens na atualidade e em constante movimento, porque faz parte de estratégias políticas, sociais e econômicas. Por isso, é frequentemente debatido nos meios acadêmicos, nas reuniões das grandes agências que fomentam as políticas para a educação, nas negociações econômicas, nos fóruns de discussões, no ensino básico, no ensino superior e nas instituições educativas. Em razão disso, torna-se dinâmico, com inesgotáveis abordagens e necessidade de novas pesquisas.

Observa-se nos trabalhos bibliográficos já realizados que as concepções sobre as políticas públicas educacionais vão desde uma visão pessimista, principalmente quando se referem à baixa qualidade do ensino e à escassez de recursos financeiros destinados à educação, a uma visão libertadora, quando se constata que, na atualidade, este tema está incluído nos questionamentos dos eventospromovidos pelas instituições públicas e que, com base neles, consegue-se perceber algumas mudanças sociais e estruturais na sociedade.

Contudo, a forma como essas políticas são concebidas depende da compreensão que se tem das interferências que elas sofrem, como as do Fundo Monetário Internacional (FMI), do Banco Mundial, de 
agências multilaterais e de outros órgãos que, de certa forma, esperam algum resultado econômico com as recomendações feitas por ocasião das formulações das políticas de estado para a educação.

Pretende-se neste artigo, inicialmente, discorrer, de forma geral, acerca do percurso histórico das políticas públicas educacionais no Brasil. Posteriormente, especificar este tema na inserção e na participação das populações indígenas e o seu processo de escolarização com base nessas políticas. Por fim, verificar o acesso dos indígenas ao ensino superior, centralizando essa reflexão naexperiência da Ufopa.

A justificativa para a abordagem da inserção dos indígenas nas políticas públicas educacionais no Brasil fundamenta-se na concepção de Garcia (2001, p. 11): “ainda é a escola pública a única possibilidade de democratização da educação. É ali que as classes subalternas buscam a consolidação, aprofundamento e ampliação dos saberes que trazem de suas vivências e experiências".

Considerando essa afirmação e o avanço na legislação pertinente ao tema, presume-se relevante o enfoque sobre a participação das populações indígenas no cenário educacional brasileiro, tendo em vista que no período colonial essas populações atuaram como personagens de um processo de integração na sociedade nacional por meio da catequização e, na atualidade, apresentam-se como protagonistas de uma história na qual nem sempre elas atuam.

\section{As políticas públicas educacionais: um breve histórico}

Inicia-se esta discussão com as concepções de Paulilo (2010) e seus estudos sobre essas políticas e as controvérsias sobre a existência ou não de sua historiografia. De modo geral, existe uma concepção que aponta para a ausência de estudos historiográficos a respeito das públicas políticas educacionais. Essa perspectiva menciona que há apenas um diálogo dessas políticas com as ciências, entre elas a Sociologia. Contrapondo-se a essa perspectiva, existem aqueles que afirmam que as políticas públicas educacionais estão historicamente situadas. 
Sobre a primeira perspectiva, Paulilo (2010, p. 482) afirma: "a historiografia da educação sequer tem apresentado estudos sob o rótulo de história das políticas educacionais". Reforçando a concepção de Paulilo, Sanfelice (2004 apud PAULILO, 2010, p. 482) ressalta que "o tratamento histórico das políticas públicas em educação não é outra coisa senão história política".

De acordo com essa primeira abordagem, nota-se que os estudos sobre as políticas públicas educacionais são registros de práticas que variam de acordo com o período histórico em que elas foram implantadas. São registros dinâmicos, alteráveis, que dependem do tipo de política que aquele momento histórico, social e econômico pretendia para a educação.

Na segunda concepção, Popkewitz (2004 apud PAULILO, 2010, p. 484) analisa as reformas públicas educacionais como "uma inserção de saberes com o poder e com as práticas situadas historicamente", concentrando-se nas relações de poder entre instituições de saber, como as agências governamentais, os grupos universitários, as fundações filantrópicas e as "escolas" de pesquisa. $O$ autor ressalta a importância da história e das epistemologias nelas difundidas para o estabelecimento e a constituição de um processo de escolarização.

Dialogando com Popkewitz (1997) sobre a existência de estudos das políticas públicas educacionais, Nunes e Carvalho (2004 apud PAULILO, 2010, p. 484) afirmam que

A política educacional também se define como uma prática social. Não obstante, esse objeto de estudo mostra-se compreensível a partir da materialidade dos seus dispositivos e das lutas de representação que fomentam tanto na macroestrutura do Estado quanto na micropolítica das disputas cotidianas. A consequência é que o estudo da política educacional no âmbito dessa história se realiza a partir de uma crítica documental, capaz de construir como representação de um real os vestígios de uma prática. 
Do ponto de vista histórico, compreende-se que os vestígios mencionados referem-se aos estudos realizados sobre essas políticas registrados na história e as práticas difundidas sobre elas.

Na interpretação da Sociologia e dos estudos epistemológicos, percebe-se que são grandes as contribuições da história na compreensão das políticas educacionais. Popkewitz (2004 apud PAULILO, 2010, p. 484) menciona que, em uma perspectiva conceitual, o enfoque dado pela história sobre as políticas educacionais facilita uma análise dos padrões delas, tanto no que se refere aos padrões do passado como aos padrões atuais. Segundo esse autor, a história registra as mudanças e as formas ocorridas no âmbito educacional.

Independentemente da centralização do seu estudo na história, as políticas públicas em educação, em alguns momentos, são concebidas como possibilidades de inserção de modelos educacionais e culturais e fazem parte de um expressivo número de projetos de escolarização que, para serem implantados, exercem forte influência sobre os sistemas de ensino e suas políticas.

Compreender as políticas educacionais está muito além de simplesmente estudar as decisões do poder público, de entender o pensamento dos líderes políticos e dos organismos nacionais e internacionais que atuam sobre elas; está acima da concepção daquilo que essas políticas representam econômica e politicamente e como ação de governo.

No Brasil, a história dessas políticas segue um percurso que remonta ao final do século XIX e início do século XX. Santos (2011, p. 2) assim o descreve:

Foi somente em fins do século XIX e início do século XX, no contexto da Primeira República - quando o Estado brasileiro Oligárquico deslocava-se para uma "arrumação"Moderna/liberal, assumindo um modelo intervencionista -, que a educação começou a ser reclamada como necessária ao "desenvolvimento do país". 
A sistematização dessas políticas, bem como suas regulamentações, foi aos poucos sendo legitimada pelos marcos legais que impulsionaram suas reformas posteriores. Destaca-se, dentre esses limites regulatórios, o Manifesto Pioneiro, impulsionado pela Reforma Francisco Campos, na década de 1930, que é considerado um período importante nas definições das diretrizes dessas políticas na educação brasileira.

Embora o Manifesto Pioneiro tenha sido importante para a afirmação das políticas públicas educacionais, ressalta-se que um dos fatores responsáveis pela demora na definição dessas políticas foi a falta de um Estado-ação atuante que se tornasse responsável pelas diretrizes dessas políticas, conforme menciona Santos $(2011$, p. 1):

A trajetória histórica das políticas educacionais no Brasil parece revelar uma nítida ligação com a forma conservadora e patrimonialista com a qual o Estado e a sociedade brasileira foram sendo forjados. Assim, em um cenário social cujas bases centravam-se em um modelo econômico agroexportador e na mão de obra escrava, a preocupação com o direito à educação veio aparecer tardiamente.

Os manifestos realizados durante a Revolução de 1930 foram significativos para o surgimento de novas concepções sobre a educação brasileira, pois a partir deles surgiram inquietações de educadores, de algumas organizações, além de outros movimentos que clamavam pela organização das diretrizes das políticas públicas para a educação.

Nos fins da década de 20 e 30, parecia, assim, que estávamos preparados para a reconstrução de nossas escolas. A consciência dos erros se fazia cada vez mais palpitante e o ambiente de preparação revolucionária era propício à reorganização. O país iniciou a jornada de 30 com um verdadeiro programa de reforma educacional. Nas revoluções, como nas guerras, sabe-se, porém, como elas começam, mas não se sabe como acabam (TEIXEIRA, 1976 apud SANTOS, 2011, p. 2). 
Posteriormente ao Manifesto Pioneiro, o Brasil passou por várias reformas na educação. A expectativa estava na criação daprimeira Lei de Diretrizes e Bases da Educação Nacional, de 1961, que propiciou esperanças por melhorias no ensino, porém a educação no país ainda estava em desvantagem e com consideráveis prejuízos, pois, mesmo depois da criação da LDB, continuou-se com acentuada prioridade do ensino privado e algumas limitações em relação ao ensino público.

No cenário do período militar, a educação possuía um caráter desenvolvimentista, era regulada e seguia as recomendações estabelecidas nos acordos entre governo e organismos internacionais. Nesse período, a educação brasileira tinha como principal objetivo a garantia de participação em um cenário nacional abrangente de educação em que o ensino, a pesquisa e a extensão eram dissociados, com característica e estrutura departamentais.

A partir de 1980, algumas mudanças começaram a surgir no cenário educacional. Para que isso ocorresse, houve uma ruptura com as concepções existentes a respeito do modelo de educação vigente. Nesse período, a luta pela democratização da educação se apresentava um pouco mais resistente às medidas impostas. Essas lutas trouxeram melhorias para a educação do país, conforme aponta Santos (2011, p. 6):

a) Melhoria na qualidade na educação, inclui-se neste âmbito: preocupações com a permanência do educando na escola e com a distorção idade-série; merenda escolar, transporte e material didático; redução do número de alunos nas salas de aula; melhoria nas instalações das escolas; formação adequada aos professores; revisão dos métodos; mudança nos conteúdos dos livros didáticos.

b) Valorização e qualificação dos profissionais da educação, plano de carreira nacional.

c) Democratização da gestão: reivindicavase a democratização dos órgãos públicos de administração educacional; descentralização administrativa e pedagógica; gestão participativa dos negócios educacionais; eleição direta e secreta para dirigentes de instituições de ensino; construção 
de comissões municipais e estaduais de educação autônomas e amplamente compostas para acompanhar a atuação política educativa; colegiados escolares eleitos pela comunidade escolar.

d) Financiamento: defendia-se a ideia de que deveriam existir verbas públicas exclusivas para a educação.

e) Ampliação da escolaridade obrigatória: abrangendo creche, pré-escola, primeiro e segundo graus.

Com o fim do regime militar e a realização de eleições para presidente e eleições nos estados e municípios, a educação brasileira vivencia um novo momento e a projeção para uma educação com a possibilidade de abertura de espaços para as contribuições de intelectuais e de educadores e a proposta de um modelo educacional mais voltado para os verdadeiros anseios da sociedade brasileira, como a criação de uma nova LDB.

As discussões sobre a nova LDB (Lei no 9.394, de 20 de dezembro de 1996) começaram a ser materializadas a partir dos anos de 1990. Novamente, expectativas e esperanças por melhorias e novos paradigmas para educação foram projetadas.

É possível dizer que as portas da década de 1990 foram abertas com expectativas positivas em relação ao "delinear" das políticas educacionais. Expectativas essas que, ao longo do processo, foram se desfazendo devido às mudanças instauradas tanto na curta gestão de Fernando Collor de Mello/ Itamar Franco quanto na gestão de Fernando Henrique Cardoso na presidência do país, bem como nos rumos que foi assumindo o processo de elaboração e condução da Lei de Diretrizes e Base da Educação de 1996 (SANTOS, 2011, p. 7).

Segundo a autora, as expectativas com relação à materialização da nova LDB foram frustrantes, pois não correspondiam às mudanças tão esperadas e seu texto não passava de um habilidoso“jogo linguístico que invertia termos e sinais, de modo a torná-los condizentes com os novos 
paradigmas que referenciavam a mudança almejada para a educação no país" (SHIROMA; MORAIS; EVANGELISTA, 2002 apud SANTOS, 2011, p. 7).

Apesar de a LDB de 1996 não contemplar as expectativas previstas para a educação brasileira, pontos importantes foram adicionados ao seu texto e, com base nela, foi possível ver alguns avanços no sistema educacional em relação ao que se tinha em séculos passados, como a inserção de tópicos considerados relevantes para a educação básica. Dentre eles: a) Educação infantil constituída pela creche para crianças de zero a três anos e pré-escolas para crianças de quatro a seis anos; b) Ensino fundamental constituído por oito anos; c) Ensino médio constituído por três séries (SANTOS, 2011, p. 8).

No século $X X$, o Brasil vivencia experiência da hegemonia capitalista, principalmente no governo de Fernando Henrique Cardoso, e passa por um processo de reestruturação. Esse modelo trouxe reflexos para a educação. Segundo Dourado (2002, p.235), “O processo resultante de uma nova fase de reestruturação capitalista é marcado por políticas de centralização, de diferenciação e de diversificação institucional e, especialmente, de privatização da esfera pública".

Nesse cenário, a educação, assim como outras políticas sociais, não estava inserida na lista das prioridades das políticas de governo. A forte relação entre governo e o setor privado implicaria alterações nas esferas sociais, entre elas a educacional. Incidiram sobre a "organização jurídica das instâncias educativas, nos novos processos de regulação, gestão e formatos de privatização na arena educacional" (DOURADO, 2002, p. 236).

Mais recentemente, nos primeiros anos de governo do presidente Lula, não foram observadas grandes mudanças com relação às políticas educacionais. Priorizaram-se, nesse primeiro momento do governo, as políticas educacionais implementadas no governo anterior.

Os primeiros anos do governo Lula foram marcados muito mais por permanências que por rupturas em relação ao governo que o antecedeu. Os dois primeiros-ministros da Educação não chegaram 
a estabelecer uma agenda que se contrapusesse à anterior. Apesar das tentativas do Ministério da Educação nesses primeiros anos de imprimir nova marca à política educacional em curso, no geral observou-se a mesma fragmentação e descontinuidade da década passada (OLIVEIRA, 2011, p. 237).

Constata-se, a partir do percurso histórico da educação no Brasil, que pouco resultado positivo ocorreu nas políticas educacionais do país. Infelizmente, as várias tentativas de mudanças e de inserção de reformas nas políticas educacionais adquiriram características de um modelo compensatório. Uma tentativa de refazer um percurso, de corrigir falhas do passado, utilizando os mesmos mecanismos das décadas anteriores, os quais também não se efetivaram.

De modo geral, a historiografia mostra que sempre houve dificuldade na implementação de políticas públicas educacionais que favorecessem o processo de ensino-aprendizagem. Com relação à implantação de políticas educacionais específicas para populações com diversidades étnicas e culturais, pouco ou quase nada se viu nessas políticas propostas ao longo dos tempos e dos séculos.

\section{A escolarização indígena}

O desenvolvimento do processo escolar indígena teve início em meados da segunda metade do século XVI, com uma ideologia dominante de que os índios precisavam ser preparados para se adaptarem à sociedade colonial vigente. Nesse período, a educação escolar dos indígenas ficou sob a responsabilidade das missões religiosas católicas, conforme destaca Santos $(2011$, p. 4):

No Brasil colonial a intenção era civilizar/catequizar o indígena. Já no Brasil republicano (até a Constituição de 1988), a intenção era integrar o indígena à sociedade nacional. Essa mudança aconteceu devido a denúncias nacionais e internacionais quanto ao não respeito aos povos indígenas. 
Inicialmente, os jesuítas se encarregaram de educar esses povos em forma de catequização, e o estado laico também interferiu na educação dos índios ainda no período colonial. Posteriormente, no período imperial, outras tentativas e pretensões de educar os povos indígenas começaram no período colonial com a alfabetização. Segundo Melià (1979 apud FERRARO; SCHAFER, 2007, p. 5):

\begin{abstract}
A argumentação que justifica a alfabetização do indígena é mais ou menos essa: o indígena deve conseguir se intercomunicar, deve saber lidar como/ resolver os problemas criados pela sociedade envolvente. $O$ indígena deve saber defender-se do branco, para isso é necessária a alfabetização. Como se a alfabetização por si mesma fosse capaz de resolver os problemas trazidos pelo contato.
\end{abstract}

Sobre a preocupação com a alfabetização dos indígenas, Graff (1995 apud FERRARO; SCHAFER, 2007, p. 6) trata esse assunto como "o mito da alfabetização". Segundo o autor, estavam atribuídos à alfabetização dos indígenas "o desenvolvimento econômico, tecnológico e político, a modernização, a estabilidade política, o controle de natalidade, entre outros".

Para Melià (1979 apud FERRARO; SCHAFER, 2007, p. 6), o“pano de fundo" da alfabetização dos indígenas era a obtenção de recursos tanto por parte do governo como de algumas Organizações não Governamentais (ONGs) que, muitas vezes, conseguiam esses recursos com a venda da mão de obra indígena.

Em 1910, após inúmeras pressões, o governo criou o Serviço de Proteção ao Índio (SPI), órgão responsável pelo gerenciamento de todos os assuntos que diziam respeito aos índios, inclusive a educação.

A partir da criação do SPI, houve mudanças no gerenciamento da educação dos povos indígenas. Inicialmente, eram os padres que investiam na catequização dos índios; posteriormente, o SPI passou a tratar do processo de incorporação dos indígenas no trabalho agrícola e doméstico, sendo inclusive incluídas nos currículos escolares as disciplinas "Práticas Agrícolas" e "Práticas Domésticas". 
Ferraro; Schäfer (2007, p. 4) afirmam que, em 1967, após fortes denúncias contra o SPI a respeito de massacres sofridos pelos índios, ocorreu a extinção do SPI e foi criada a Fundação Nacional do Índio (Funai), que passou a zelar pelos assuntos relacionados aos indígenas.

Embora as práticas da Funai fossem bem parecidas com as já existentes durante a vigência do SPI, algumas de suas propostas e atuações foram bem mais significativas para esses povos, apesar da inexistência de recursos para a implementação de políticas voltadas para os índios. Naquele momento, sua preocupação maior era com o desenvolvimento interno do país.

A FUNAI, com esse caráter empresarial, está preocupada em obter recursos financeiros e passa a implantar, nas terras indígenas, projetos econômicos que visem tal fim. Assim, segundo Santos (1975), os postos da FUNAI que tinham melhores condições para executar atividades agrícolas passaram a investir sistematicamente no cultivo de trigo, soja, feijão ou milho. Foram também implantadas serrarias nas áreas indígenas que tinham recursos florestais, e quando não havia recursos para isso eram concedidos direitos, pela FUNAI, de serrarias privadas explorarem a área (SANTOS, 1975 apud FERRARO; SCHAFER, 2007, p. 4).

A Funai, na sua atuação no processo de educação dos indígenas, não implementou grandes modificações, optando pela continuidade do que já existia nos currículos escolares e nas secretarias de educação dos estados e municípios. Sua única distinção em relação às propostas já vigentes nessas secretarias foi a criação do ensino bilíngue nas escolas, com prioridade para a língua materna.

Vale destacar que, em relação ao ensino bilíngue proposto, não havia nenhum programa da própria Funai voltado a esse ensino nem pessoas preparadas para esse trabalho. Em razão disso, a Funai recorreu ao Summer Institute of Linguistics (SIL), um organismo fundamentalista religioso que já existia no Brasil desde 1959 e que tinha como principal objetivo traduzir a Bíblia nas diferentes línguas, entre elas as línguas 
das tribos. Segundo Ferraro e Schafer (2007, p. 4), o convênio com o SIL encerrou-se em 1977 e em 1999 tanto o Ministério da Educação como o Ministério da Cultura impediram, por meio de um parecer oficial, que esse instituto continuasse suas atividades no Brasil na tradução do Novo Testamento para os povos indígenas.

Apesar de fazer parte dos movimentos sociais, das assembleias e dos debates, no Brasil, as articulações sobre a educação para os indígenas começaram tardiamente e foram melhor sistematizadas em 1974. Com o intuito de melhorar a situação educacional dos povos indígenas, organismos e instituições foram criados, como a União das Nações Indígenas (UNI), designada para realizar as mobilizações sociais na defesa dos direitos dos indígenas a respeito de sua educação escolar. Com a representatividade da UNI, os movimentos indígenas passaram a contar com o apoio de instituições governamentais e não governamentais, que tinham em vista propósitos e negociações políticas e econômicas para a sua atuação, como a venda da mão de obra indígena.

Do ponto de vista da Antropologia, destaca-se que os povos indígenas sempre conviveram em uma relação de conflito com a sociedade considerada nacional. A relação existente era a de dois mundos antagônicos, separados por duas sociedades diferentes. De um lado, um povo considerado agente colonizador; de outro lado, os índios. A tentativa de inclusão e inserção dos índios na sociedade dos não índios foi marcada por dificuldades enfrentadas pelos índios ao serem inseridos em uma sociedade da qual não faziam parte e com extremas desigualdades.

A sociedade na qual se pretendia inserir os indígenas é descrita por Secchi $(2011$, p. 5) como um cenário de interesses opostos, "marcado pelos contrastes, por forças desiguais e resistências heroicas", afirmando ainda o autor que "as 'sociedades indígenas' estão lutando pelos direitos constitucionais, pelo direito de preservar a identidade e a diferença, pelo direito de construir seus projetos do futuro". São tentativas de consolidação de uma educação diferenciada e de uma política educacional que considere as pluralidades cultural e linguística trazidas pelos povos indígenas. 
Por mais que nos esforcemos a oferecer aos índios uma educação escolar que lhes seja respeitosa, ela será sempre, para eles, algo que remete a um modelo exógeno de educação. Desde o início das discussões sobre a melhor escola para os índios, os especialistas têm lembrado que se deve diferenciar uma "educação indígena" de uma "educação escolar indígena" (COHN, 2005, p. 2).

A complexidade na elaboração de uma proposta educacional diferenciada é ilustrada por Ferraro e Schäfer (2007, p. 3), que ressaltam a importância de estabelecer a distinção entre "educação indígena" e "educação escolar indígena", para melhor compreender as especificidades, as necessidades e particularidades desses povos.

Para esses autores, a proposta desses dois modelos educacionais representa duas formas distintas de educação para os indígenas: a primeira se refere a uma "educação formal", que está ligada à vida toda dos indígenas; é uma formação humana, desenvolvida por eles mesmos de acordo com suas técnicas e crenças. A segunda se refere a uma educação "formal nacional", caracterizada pela existência de "regimentos, calendários escolares, planos de aula, salas de aula e que faz parte de um período da vida do ser humano", o período da escolarização adquirida nos ambientes escolares.

A preocupação em compreender a distinção entre "educação indígena" e "educação escolar indígena" demonstra que, antes da implantação de políticas educacionais específicas para indígenas, fazse necessário estabelecer questionamentos norteadores para essas políticas, a fim de garantir seu funcionamento. Há a necessidade de conhecer previamente as especificidades dessas populações atendidas com essas políticas. Nesse sentido, Nascimento (2004, p. 5) faz as seguintes indagações:

A criação de escola específica e diferenciada será para qual índio? Qual o autoconceito desses grupos? Quais as certezas e incertezas de cada grupo indígena? Quais são suas referências para construir a sua identidade cultural e estabelecer um estatuto de reivindicações 
baseadas nas novas sínteses culturais que as diferentes formas de interação o levaram a construir?

Os questionamentos acima aludem à preocupação da autora com a interpretação sobre o que deve ser considerado como universal e o que deve ser considerado como particular. Também sobre a função da escola ao criar escolarização específica e diferenciada em um mesmo espaço, pois se entende que no espaço escolar deve ocorrer a democratização dos saberes, e não a separação e a segregação dos mesmos. A autora aponta para outro questionamento: será esta a melhor maneira de inserção dos indígenas na sociedade e na obtenção de saberes?

Constata-se que durante muito tempo a preocupação em educar os indígenas representava uma forma de dominação, imposição de um conhecimento e tentativa de transformá-los para que eles pudessem conviver em uma sociedade não índia. Em razão disso, interpretações errôneas de que os indígenas não necessitavam de educação ou que a educação voltada para eles era um processo informal foram sendo difundidas.

Durante muito tempo e ainda hoje foi/é uma forma de dominar e impor um determinado tipo de conhecimento; foi/é uma forma de adaptar o indígena a uma determinada sociedade, de transformá-lo apto a cumprir certos requisitos necessários para sobreviver na sociedade do "branco", ou seja, a educação por muito tempo foi uma forma de transformar o índio em mão-de-obra qualificada e barata (quando não escrava) (FERRARO; SCHAFER, 2007, p. 2).

Assim, percebe-se que o processo escolar indígena é complexo e foi posto em prática tardiamente, remontando a uma lamentável parte da história de dizimação e invisibilidade. Foram marcas traumáticas do período colonial, quando suas culturas foram ocultadas e lhes impuseram uma educação como se eles não possuíssem nenhuma. Houve uma ocultação dos conhecimentos de seus ancestrais, o que justifica, segundo Luciano (2006 apud PEREIRA; FRANCO, 2010, p. 7), "a ideia errônea de que os indígenas não possuem nenhum tipo de educação". 
Isto reforça que ainda existem manifestações preconceituosas no que diz respeito à presença dos povos indígenas nos espaços educacionais, além da ausência de conhecimentos sobre a existência dos conhecimentos trazidos pelos povos indígenas.

\section{A participação dos indígenas e as políticas públicas educacionais}

Inicia-se esta discussão enfatizando a importância dos dispositivos legais sobre o acesso à educação, previstos na Constituição Federal (art. 205), na LDB (art. 26), bem como em decretos e em regulamentações e, mais recentemente, na Lei Federal no 12.711/2012 (art. $5^{\circ}$ ), que estabelece reserva de vagas nas instituições de ensino superior para "autodeclarados pretos, pardos e indígenas". Assim, notase uma abertura no que diz respeito ao acesso ao saber para esses povos. Da criação da LDB e da promulgação de outras leis, como a Lei no 10.588/2002, que instituiu o programa Diversidade na Universidade, sugiram diversas políticas públicas que visavam/visam a uma melhor relação entre o Estado e as populações indígenas.

Vale destacar que, durante um longo período da história, os indígenas não participaram, ou se participaram foi com pouca expressividade, das políticas públicas e dos processos educacionais decisórios voltados a eles. Secchi (2007, p. 16) classificou em quatro períodos a atuação indígena nos processos educacionais:

a) Período de exclusão indígena: é um período de exclusão dos índios das políticas públicas. Nesse momento, atuavam em favor dos índios o Serviço de Proteção aos Índios (SPI) e a Fundação Nacional dos Índios (FUNAI), esta última estava iniciando sua atuação. Esses dois órgãos raramente se envolviam em iniciativas voltadas para as comunidades indígenas. A única preocupação com os indígenas era sua localização geográfica e a identificação da grande diversidade cultural existente. A participação dos índios se dava marginalmente como observadores ou prestadores de serviços. 
b) Período de inclusão compulsória (décadas de 1970 e 1980): esse momento é representado por um conjunto de iniciativas que teve como objetivo a integração nacional e o desenvolvimento do CentroOeste e da Amazônia.

c) Inclusão solidária (década de 1990): esta fase apresenta duas características: uma que é marcada pela tentativa de inclusão das sociedades indígenas no âmbito das políticas públicas voltadas às "populações desassistidas" representadas por políticas assistenciais que visavam à participação do índio na sociedade. Outra que representava uma busca dos valores étnicos, culturais e de cidadania dos povos indígenas.

d) Protagonismo indígena: trata-se do período atual que se projeta para o futuro e que tem o seu nascedouro no próprio movimento indígena e nas instituições apoiadoras. Esse momento concebe as políticas públicas como partes integrantes do Plano de Vida de um povo ou de uma comunidade. Consideramse os projetos educacionais e de desenvolvimento em seus múltiplos aspectos e supõe a participação indígena em todas as suas fases: definição das prioridades, elaboração, busca de financiadores, planejamento e administração dos recursos e das ações, acompanhamento, avaliação, registros.

Os períodos retratados anteriormente permitem compreender a participação dos indígenas nas políticas públicas e a sua autonomia para atuar, relacionar-se e manter diálogo com as instâncias do poder público quanto ao seu processo de escolarização. A participação e a manifestação dos indígenas sobre qual modelo de educação que atenda melhor às suas especificidades é praticamente inexistente em todos os períodos mencionados. Para Secchi (2007, p. 10), “a escola indígena adequada será aquela que, incorporada à comunidade, Ihe ensejará maior capacidade de decisão sobre si e sobre os demais elementos culturais advindos do convívio intersocietário".

Ainda há pouca preocupação com o ensino voltado para as diversidades culturais, para os afrodescendentes, considerando sua especificidade e seu caráter diferenciado ao longo da história. 
Nesse sentido, é possível pensar que a abertura para o acesso dos indígenas à educação só passou a existir mediante a obrigatoriedade do cumprimento das leis. Lima $(2012$, p. 4) ilustra essa afirmação: “No Brasil, a política educacional indigenista é assegurada sobre os efeitos da Constituição de 1988, da Lei de Diretrizes e Bases da Educação Nacional e os prismas de uma Política Nacional para a Educação Escolar Indígena definida pelo Ministério da Educação".

Embora seja perceptível a implementação de políticas de inclusão, acesso e permanência dos povos indígenas nas instituições de ensino, constata-se, todavia, que reflexões a respeito da inserção e da convivência do indígena em uma sociedade não índia e da sua atuação no processo de interculturalidade devem ser constantes.

Apesar dos avanços, reconhecidos, por parte dos
povos indígenas, para uma sociedade fortemente
educada sobre os parâmetros do etnocentrismo, da
cultura da acumulação, da hierarquização do saber e
que hoje caminha sob os princípios do neoliberalismo
e da globalização, as conquistas legais que mudam o
eixo das relações entre povos indígenas e a sociedade
não-índia não garantem aos índios: autonomia para
decidirem como gostariam de ser tratados como
cidadãos; que a sociedade não índia mude os seus
(pré) conceitos e o seu olhar de discriminação e
desrespeito sobre eles; que possam participar
coletivamente como produtores e organizadores de
conhecimento (NASCIMENTO, 2004, p. 18).

Apenas garantir, por força de leis, o acesso dos indígenas aos saberes disponibilizados pelas instituições de ensino e, dessa forma, considerar que existe democratização da educação não é suficiente. É necessário pensar nas peculiaridades dos povos indígenas, na forma de inseri-los na sociedade, nas escolas e nas universidades de maneira a garantir sua permanência e um ensino de qualidade, considerando suas especificidades e sua diversidade cultural.

Não basta a escola para os indígenas, mas uma escola indígena com suas diferenças e especificidades. Não basta a escola indígena, são necessárias as condições 
para mantê-las, programas, currículo e formação de professores. São signos que estão, até então, fora da estrutura psíquica da comunidade indígena, porém entendem que é necessário dominá-los, para que a escola possa ser um instrumento de continuidade de sua identidade cultural (LIMA, 2012, p. 6).

Contudo, vale ressaltar que, apesar das exigências legais que propagam e defendem uma educação que priorize a interculturalidade, observa-se que a realidade da educação voltada para os povos indígenas é bem diferente daquilo que preconizam essas regulamentações e as normas legais. O ensino para esses povos ainda enfrenta obstáculos para o seu pleno funcionamento e não segue um processo diferenciado de ensino de que os povos indígenas necessitam. Nesse sentido, Melchior (2009, p. 372) afirma que "A escola para ser indígena, necessariamente, deve propiciar o acesso aos saberes da cultura dominante, porém, antes disso, precisa estar priorizada a cultura local, os saberes a organização social e a visão de mundo indígena, que antecedem aos da cultura dominante".

Pensar em uma educação voltada para os povos indígenas, considerando suas especificidades, significa refletir sobre vários aspectos da educação, dentre eles a formação de professores e sua prática pedagógica, e pensar em uma proposta pedagógica de ensino que proporcione a interculturalidade na sala de aula, e não externa a ela.

\section{0 indígena e o ensino superior}

Em relação ao ensino superior, percebem-se avanços em relação ao acesso dos povos indígenas a esse nível de ensino, principalmente a partir da promulgação da Lei no 12.711 , de 20 de agosto de 2012. No ano de 2001, a Universidade de Brasília (UnB) e a Universidade do Estado do Rio de Janeiro (Uerj) implantaram o primeiro programa com reserva de vagas para indígenas, os quais puderam ter acesso aos cursos regulares de graduação dessas instituições de ensino superior.

Posteriormente, conforme destacam Brito e Doebber (2014, p. 2), houve a experiência no estado do Paraná com reserva de três 
vagas nos cursos de graduação aos estudantes indígenas em todas as universidades estaduais paranaenses (Unioeste, UEM, UEL, UEPG, Unicentro, UENP, UEP).

Após a regulamentação das ações afirmativas nas universidades federais brasileiras, a partir da promulgação da Lei no $12.711 / 2012$, outras instituições de ensino superior e técnico passaram a aderir a programas e políticas que permitiram o acesso desses estudantes, além de outras populações, a essas políticas. Essa lei, chamada de Lei de Cotas, fortalece os debates, já iniciados, sobre o acesso e a permanência de populações consideradas minoritárias nas instituições de ensino superior.

A instituição do programa de Reestruturação e Expansão das Universidades Federais (Reuni), criado pelo Decreto $\mathrm{n}^{\circ}$ 6.096, de 24 de abril de 2007, fortaleceu os debates sobre as políticas de acesso de indígenas às instituições federais, na medida em que exigiu das instituições de ensino superior adequação e novas configurações para as suas políticas e programas de ensino e ampliou o processo de inclusão e redução das desigualdades em relação ao ensino superior para populações com situação socioeconômica vulnerável, proporcionando, com essa política, maior igualdade de oportunidades na educação.

O objetivo geral do Reuni previu

Criar condições para a ampliação do acesso e permanência na educação superior, no nível de graduação, para o aumento da qualidade dos cursos e pelo melhor aproveitamento da estrutura física e de recursos humanos existentes nas universidades federais, respeitadas as características particulares de cada instituição e estimulada a diversidade do sistema de ensino superior (BRASIL, 2007, p. 11, grifo nosso).

Com a implementação do Reuni, novas instituições de ensino superior surgiram, atendendo à proposta de expansão universitária. Essas instituições trouxeram consigo políticas de ação afirmativa, possibilitando a inclusão de uma diversidade populacional ao ensino 
superior distante de espaços acadêmicos, conforme justifica o Grupo de Estudos Multidisciplinar da Ação Afirmativa (GEMAA, 2013, p. 3):

\begin{abstract}
A maior inclusão de alunos pobres, pretos, pardos e indígenas nas universidades federais deve ser creditada tanto a iniciativas das próprias universidades como também ao estímulo a medidas inclusivas proporcionadas pelo Governo Federal nos últimos anos. A liberação de verbas para as universidades federais oriunda da adesão ao REUNI foi condicionada a um compromisso social das instituições com políticas de inclusão e assistência estudantil.
\end{abstract}

Na proposta de reestruturação e expansão das universidades federais com a implantação do Reuni, está a Universidade Federal do Oeste do Pará (Ufopa), localizada na cidade de Santarém, a terceira maior cidade do estado do Pará, e com um expressivo quantitativo de populações indígenas situadas nos municípios de abrangência dessa universidade.

A Ufopa, criada pela Lei no 12.085 , de 5 de novembro de 2009, é resultante do desmembramento da Universidade Federal do Pará (UFPA) e da Universidade Federal Rural da Amazônia (Ufra), no âmbito da política de expansão das universidades federais do programa Reuni. Estão, entre os compromissos da Ufopa, a expansão regional e a melhoria do ensino superior na região amazônica.

Além do remanejamento dos discentes no processo de transição das duas Instituições Federais de Ensino Superior (Ifes) citadas, a Ufopa herdou dessas instituições os bens disponibilizados para o funcionamento e o desenvolvimento de suas atividades administrativas e acadêmicas. Essas atividades em Santarém são desenvolvidas em três Unidades Acadêmicas: Rondon, Tapajós e Amazônia. Além das atividades desenvolvidas no Campus de Santarém, a Ufopa desenvolve atividades acadêmicas e administrativas nos municípios-polo situados no oeste do Pará: Oriximiná, Óbidos, Alenquer, Monte Alegre, Itaituba e Juruti.

O modelo acadêmico da Ufopa segue a formação em ciclos: o primeiro é composto pelos cursos de licenciaturas plenas e bacharelados interdisciplinares, estes com curta duração; o segundo é composto pelos 
cursos e bacharelados específicos da graduação; o terceiro é direcionado à formação de pós-graduação stricto e lato sensu.

De acordo com o Plano de Desenvolvimento Institucional (PDI 2012-2016), a organização acadêmica da Ufopa atualmente é composta por seis institutos temáticos: Instituto de Ciências da Educação (Iced), Instituto de Ciências da Sociedade (ICS), Instituto de Ciências e Tecnologia das Águas (Icta), Instituto de Engenharia e Geociências (IEG), Instituto de Biodiversidade e Florestas (Ibef) e Instituto de Saúde Coletiva (Isco), além do Centro de Formação Interdisciplinar (CFI), unidade acadêmica responsável, em regime de colaboração com os institutos, pela Formação Interdisciplinar I, realizada pelos módulos temáticos, quais sejam: OEC, EIA, SND, IBR, LLC e SINT I. É um modelo acadêmico inovador, pautado em uma proposta interdisciplinar de ensino, e constitui a formação em ciclos integrados, visando à formação continuada.

Atualmente, a Ufopa possui um total de 31 cursos de graduação divididos entre licenciaturas e bacharelados. Possui 11 cursos de especialização lato sensu, 9 cursos de pós-graduação stricto sensu de mestrado ( 3 profissionais e 6 acadêmicos) e 2 doutorados.

Atuam, também na Ufopa, dois diretórios estudantis: o Diretório Central dos Estudantes (DCE) e o Diretório Indígena (Dain), ambos liderados por estudantes da universidade, em razão de sua atuação no movimento estudantil, e escolhidos por meio de eleição.

Para o ingresso nos seus cursos de graduação, a Ufopa adota dois processos seletivos. São eles:

- Processo Seletivo Regular (PSR), ofertado desde 2010: os alunos ingressantes são selecionados com base nas notas do Exame Nacional do Ensino Médio (Enem).

- Processo Seletivo Especial (PSE): inicialmente chamado de Processo de Seleção Diferenciada, é destinado a estudantes indígenase, a partirde 2015, também a estudantes quilombolas. Esse processo tem como objetivo a implementação da política de inclusão dos povos indígenas e quilombolas na Ufopa, 
mediante reserva de vagas, por meio de cotas destinadas aos cursos de graduação da instituição. Vale ressaltar que alguns alunos indígenas, por opção, ingressam também pelo PSR.

A expressiva presença de comunidades indígenas na abrangência da Ufopa justifica a importância dessa instituição no acesso e na permanência de populações tradicionais aos seus cursos de graduação, entre elas as populações indígenas, sendo ainda a única universidade federal com sede no interior da Amazônia, em Santarém, Pará. Dados do IBGE (2010) revelam que, do total de populações indígenas existentes no estado do Pará, $25 \%$ estão localizadas nos municípios de Santarém, Alenquer, Itaituba, Monte Alegre, Juruti, Óbidos, Oriximiná e Jacareacanga. Todos esses municípios estão situados nas abrangências da Ufopa e fazem parte da política de interiorização dessa instituição.

Segundo o Censo Demográfico (IBGE, 2010), os percentuais de populações indígenas nas abrangências da Ufopa estão ilustrados na Figura 1 a seguir:

Figura 1: Distribuição das populações indígenas nos municípios de abrangência da Ufopa.

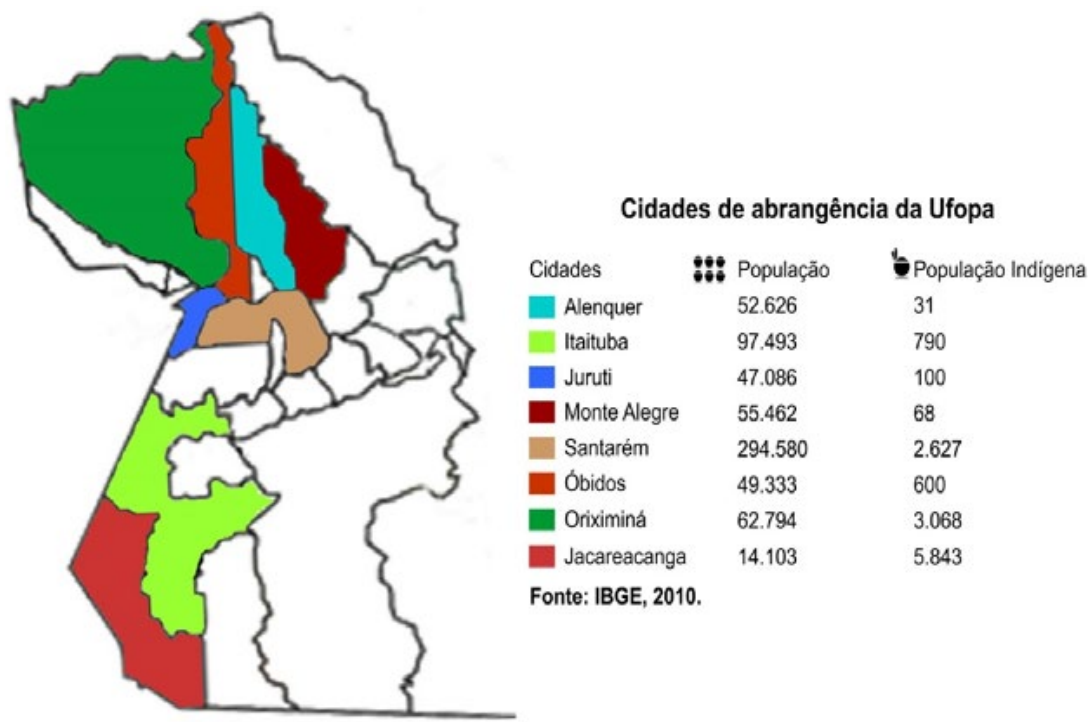

Fonte: Censo Demográfico do IBGE (2010).

242 Revista Educação e Emancipação, São Luís, v. 9, n. 3, ed. especial, jul./dez. 2016. 
Dos municípios acima listados, Jacareacanga é o único que ainda não está incluído no programa de interiorização da Ufopa, embora haja um grande número de estudantes da etnia Munduruku (oriundos desse município) que ingressaram nos cursos de graduação da instituição.

\section{A presença indígena na Ufopa}

Como já anunciado, a Ufopa realiza, desde o ano de 2010, o ingresso diferenciado para os estudantes indígenas por meio do PSE. Abaixo, na Tabela 1, segue o demonstrativo da evolução do PSE na Ufopa.

Gráfico 1: Evolução dos Processos Seletivos Especiais (PSEs/Ufopa).

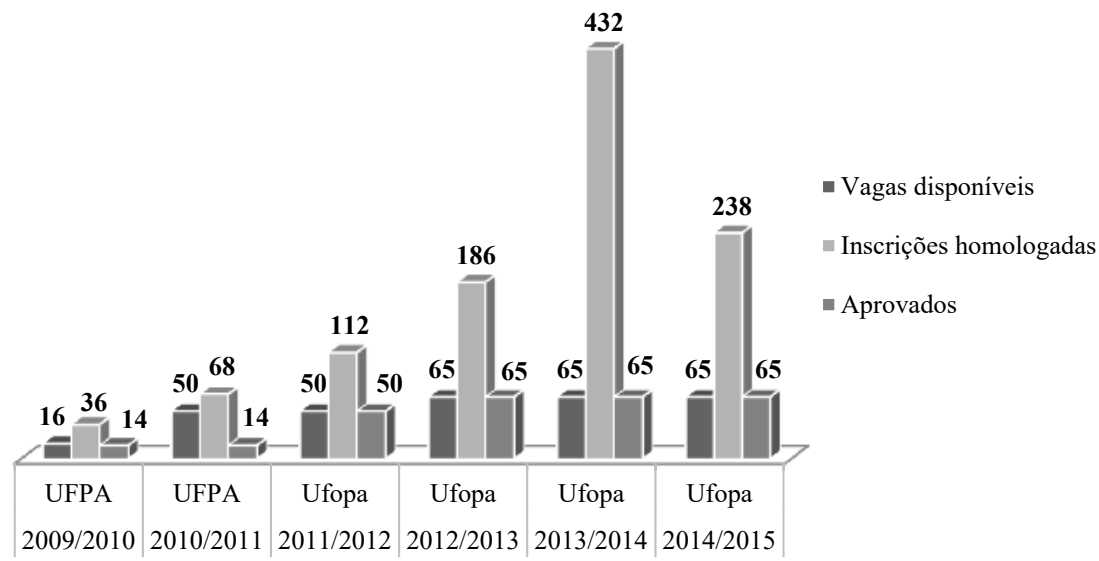

Fonte: "Planejamento Interno para Elaboração do Plano Decenal de Ações Afirmativas e Inclusão Étnico-Racial da Universidade Federal do Oeste do Pará" (Proges/Ufopa/2015).

De 2010 a 2012, o PSE da Ufopa era realizado em parceria com a UFPA, instituição que prestava consultoria à Ufopa desde a sua criação. A partir de 2012, a Ufopa passou a conduzir de maneira autônoma o PSE e aumentou o número de vagas destinadas aos estudantes indígenas, visando contemplar o expressivo percentual de indígenas com interesse em ingressar nessa universidade. No Gráfico 2, tem-se o demonstrativo do número de etnias atualmente presentes na Ufopa. Do total de etnias 
identificadas pelo SIGAA, nove ainda aparecem como não identificadas ${ }^{3}$, o que demonstra que pode haver uma diversidade étnica maior ainda dentro dessa instituição.

Gráfico 2: Etnias que ingressaram na Ufopa pelo PSE (2010 a 2015).

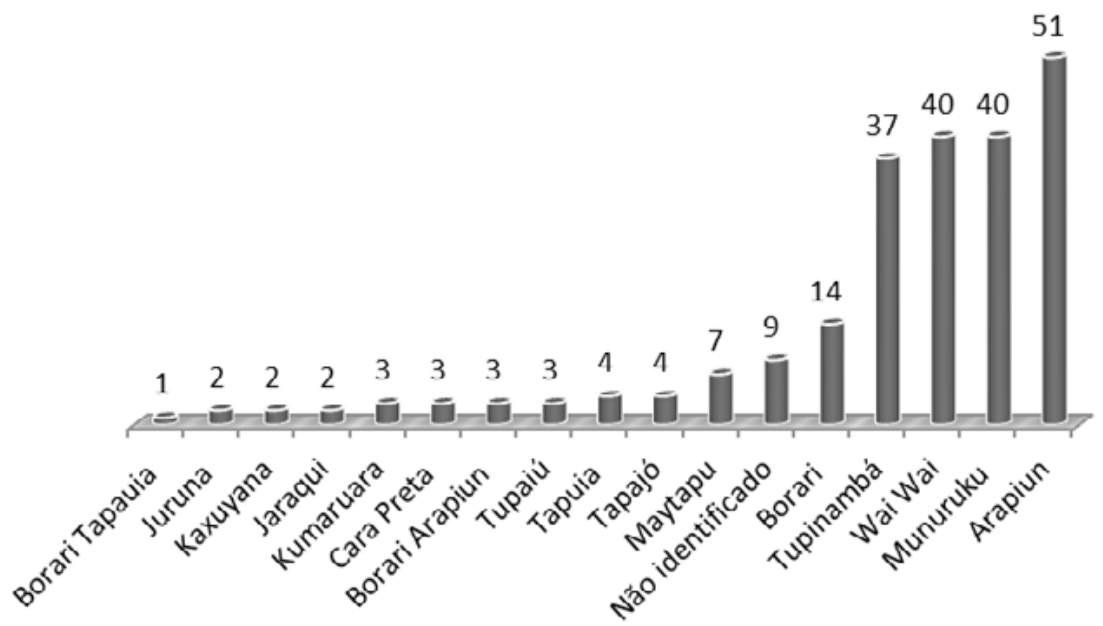

Fonte: Proges $/ 1^{\circ}$ semestre de 2015.

Em percentuais de alunos indígenas distribuídos nos seis institutos temático da Ufopa, o registo do Sistema Integrado de Gestão de Atividades Acadêmicas (SIGAA, 2015) revela que a Ufopa possui um total de 276 estudantes indígenas ativos, ingressantes pelo PSE no período de 2010 a 2015. Revela ainda a expressiva diversidade étnicacultural presente nessa instituição, conforme Gráfico 3.

3 A identificação das etnias foi realizada com base no cadastro dos estudantes indígenas para a obtenção do auxílio custeado pelo MEC. Ainda existem 9 etnias não identificadas, pois o SIGAA identifica os estudantes apenas pela raça/cor. Atualmente, esse sistema está sendo atualizado e futuramente além da raça/cor será possível também identificar a etnias de todos os estudantes indígenas da Ufopa. 
Gráfico 3: Distribuição dos estudantes indígenas nos institutos temáticos da Ufopa.

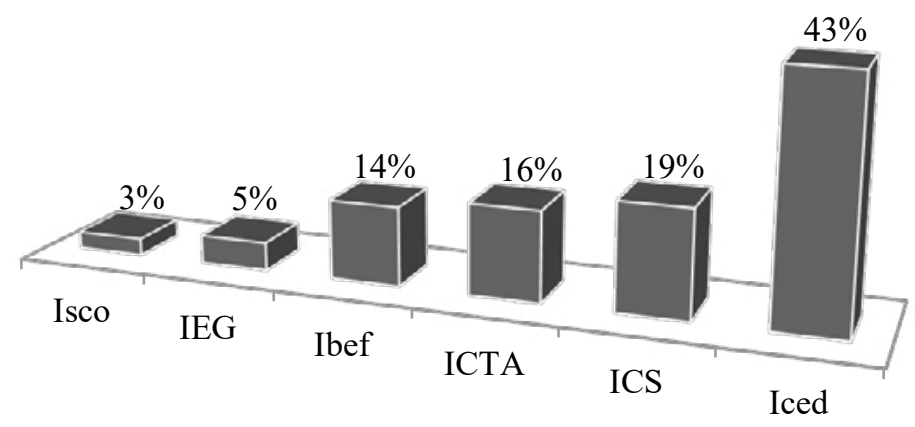

Fonte: Pró-Reitoria de Gestão Estudantil/1ºsemestre de 2015.

Antes da previsão legal sobre o acesso dos estudantes indígenas ao ensino superior, a partir da promulgação da Lei $n^{\circ}$ $12.711 / 2012$, a qual estabeleceu que as Ifes deveriam reservar, nos seus processos seletivos, vagas para estudantes pertencentes às classes menos favorecidas: índios, negros e pardos, conforme dispõe o art. $4^{\circ}$ dessa lei, a Ufopa já destinava vagas nos processos seletivos especiais voltados para os povos indígenas, uma proposta de ação afirmativa já manifestada neste texto anteriormente.

No ano de 2016, a Ufopa realizou o sexto PSE destinado à reserva de vagas para os povos indígenas. É um avanço significativo na política de ação afirmativa dessa instituição, tendo em vista possuir apenas seis anos de existência e enfrentar os desafios decorrentes da inserção de uma grande diversidade étnica que compõe seu quadro discente.

O número de processos seletivos já realizados com o instituto de garantir o acesso e a permanência dos estudantes indígenas no seu espaço acadêmico reforça a preocupação da Ufopa em ofertar uma política que permita aos estudantes indígenas igualdade no acesso ao ensino superior. Desde sua implantação, a universidade tem buscado compreender a diversidade cultural e étnica presente no seu ambiente acadêmico. A abertura para debates sobre o PSE com as lideranças indígenas, a realização de eventos e a valorização da cultura indígena 
são pontos positivos dessa instituição, que prima não só pelo ensino, mas também pelo bem-estar desses alunos durante o seu percurso acadêmico. Seu principal desafio continua sendo oferecer condições adequadas para sua permanência nesse nível de ensino.

\section{Conclusão}

Com base nas abordagens apresentadas, observou-se a emblemática das políticas públicas educacionais, da situação do processo educacional dos indígenas, da sua inserção na sociedade, da sua aquisição de saberes e participação nas políticas educacionais.

Apesar de todas as regulamentações já existentes sobre a educação indígena, percebem-se ainda grandes e profundas inquietações sobre esse tema. A raiz da dificuldade de escolarização dos povos indígenas e a sua pouca participação nas políticas públicas educacionais certamente estão associadas à forma como se pretendeu inserir esses povos na sociedade dos considerados não índios.

Duas interpretações equivocadas: uma sobre a inserção na sociedade, outra sobre a forma como os indígenas deveriam ser educados, perpassaram vários séculos, desde os jesuítas, e ainda hoje contribuem para interpretações errôneas acerca da implementação de políticas educacionais voltadas para esses povos.

Algumas indefinições e indecisões trazidas do passado ajudam no não estabelecimento de uma política pública educacional genuinamente indígena ou na redução de impactos decorrentes dela, tais como choque cultural, redução do preconceito e outras superações ainda presentes na atualidade.

Instrumentos jurídicos, como a LDB, tentaram reverter algumas situações ao inserir tópicos específicos para a educação indígena, porém a forma como a educação indígena foi concebida inicialmente, assumindo um caráter de dominação, prejudicou a formulação de 
parâmetros educacionais que resultariam em uma educação mais qualitativa aos indígenas.

Na compreensão de que o problema da educação encontra-se na base de sua história, Pereira e Franco (2010) apontam que, apesar de inúmeras reivindicações nos séculos passados, os parâmetros escolares indígenas ainda seguiam e seguem as seguintes interpretações consideradas ineficazes para seu aprendizado. Segundo essas autoras, as demandas atuais são praticamente as mesmas de séculos e anos anteriores, entre elas estão: 1) implementação de programas adequados baseados em metodologias específicas de aprendizagem, por meio de pesquisas e de acordo com os interesses e as demandas das comunidades e dos alunos, o que inclui a capacitação de recursos humanos; 2) garantias de autonomia dos projetos educacionais escolares ou não, tendo em vista as características e as necessidades definidas pelos povos indígenas, além de outras reivindicações que possam garantir sua consolidação educacional e social com todos os direitos que lhes são atribuídos por meio de leis.

Evidentemente que algumas propostas - como as políticas de ações afirmativas presentes em universidades com a reserva de vagas para os povos indígenas; a criação da proposta de expansão universitária, vinda do Reuni; a criação de cursos de graduação específicos para os indígenas, como as licenciaturas interculturais; e ainda a criação de núcleos e/ou unidades específicas para o ensino indígena, como é o caso da Universidade Federal de Roraima, que implantou o Núcleo INSIKIRAN - são marcos importantes para o fortalecimento de políticas de ensino diferenciadas, porém muitas estratégias de atendimento a essas populações ainda necessitam ser pensadas.

Na Ufopa, os desafios para garantir o acesso e a permanência dos indígenas nos cursos de graduação são latentes. Até o momento, essa universidade tem garantido o cesso dos estudantes indígenas por meio de um processo seletivo especial. Isso é significativo, pois a priori a instituição está cumprindo sua função; no entanto, as estratégias para manter a permanência e uma educação de qualidade para esses alunos, 
enquanto eles tiverem nessa instituição, necessitam ser discutidas e melhoradas. Atualmente, a Ufopa é uma referência de ensino superior não só para os indígenas, mas para todas as populações que estão ao seu redor, que certamente se deslocam e se deslocarão para essa universidade em busca de formação acadêmica.

O mais significativo, nos anos de debates acerca do acesso das populações tradicionais aos ambientes educacionais e principalmente sobre as desigualdades raciais, é que em 2001, na Conferência de Durban, houve a sinalização de que o Estado brasileiro era considerado omisso nos casos de desigualdades raciais. Essa constatação é importante, porque a partir dela cobranças mais efetivas surgiram e ainda poderão surgir em relação à postura do estado diante desse tema.

\section{Referências}

BRASIL. Decreto n 6.096, de 24 de abril de 2007. Institui o Programa de Apoio a Planos de Reestruturação e Expansão das Universidades Federais - Reuni. 2007. Disponível em: <http://legislacao.planalto.gov.br/legisla/ legislacao.nsf/Viw_Identificacao/DEC\%206.096-2007?OpenDocument>. Acesso em: 26 jan. 2016.

BRITO. P. O.; DOEBBER. M. B. Estudantes indígenas nas universidades públicas: análise a partir das produções de dissertações e teses. X ANPED - Sul, 2014. Disponível em: <xanpedsul.faed.udesc.br/arq_pdf/1202-0. pdf $>$. Acesso em: 26 jan. 2016.

$\mathrm{COHN}, \mathrm{C}$. Notas sobre a escolarização indígena no Brasil - DCSo/ UFSCAR, 2004. Disponível em:<http://www.acoesafirmativas.ufscar. br/.../notas-sobre-a-escolarizacao-indigena>. Acesso em: 30 jun. 2015.

DOURADO, F. L. Reforma do estado e as políticas para a educação superior no Brasil nos anos 90. Educ. Soc., Campinas, v. 23, n. 80, set. 2002, p. 234-252. Disponível em: <http://www.cedes.unicamp.br>. Acesso em: 15 jun. 2015. 
FERRARO, R. A.; SCHAFER, G. N. A. Escolarização e analfabetismo indígena no Brasil. UFRGS; UNILASALLE/RS, FACULDADES EST. 2007. Disponível em: <http://www.anpae.org.br/congressos antigos/ simposio2007/11.pdf>. Acesso em: 25 jun. 2015.

GARCIA, R. Para quem investigamos - Para quem escrevemos: reflexões sobre a responsabilidade social do pesquisador. Programa de Pós-Graduação da Faculdade de Educação da Universidade Federal Fluminense: Cortez, 2001.

INSTITUTO BRASILEIRO DE GEOGRAFIA E ESTATÍSTICA (IBGE). 2010. Disponível em: <http://censo2010.ibge.gov.br>. Acesso em: 05 jan. 2015.

LIMA, J. A. S. Conquistas e novos desafios das políticas públicas em educação indígena no estado fronteiriço de Roraima. 2012. Programa de Pós-Graduação em Ciência Política -PPGPOL da Universidade Federal do Rio Grande do Sul/UFRGS e o Núcleo de Estudos Comparados da Amazônia e do Caribe-NECAR, da Universidade Federal de Roraima. Disponível em: <http://www.teatros-revista/index.php/pgeografica/ article/download/.../6967>. Acesso em: 27 jun. 2015.

MELCHIOR, M. N. Políticas públicas para a educação indígena na cidade de Barra das Garças MT - UFG/UNIVAR. Anais... IX Congresso Nacional de Educação - EDUCERE. III Encontro Sul Brasileiro de Psicopedagogia - PUCPR. 2009. Disponível em: <http://www.pucpr.br/eventos/educere/ educere2009/anais/programacao.html>.Acesso em: 01 jul. 2015.

NASCIMENTO, A. C. Escola indígena: palco das diferenças. Campo Grande: UCDB, 2004.

OLIVEIRA, D. A. Das políticas de governo à política de estado: reflexões sobre a atual agenda educacional brasileira. Educ. Soc., Campinas, v. 32, n. 115, p. 323-337, abr./jun. 2011. Disponível em: <http://www.cedes. unicamp.br>. Acesso em: 30 jun. 2015.

PAULILO, L. A. A pesquisa em políticas públicas no Brasil numa perspectiva histórica. Estudos RBEP. R. bras. Est. pedag., Brasília, v. 91, n. 229, p. 481-510, set./dez. 2010. Disponível em:<http://www.rbep.inep.gov.br/ index.php/RBEP/article/view/1606/1361>. Acesso em: 25 jun. 2015. 
PEREIRA, D. S.; FRANCO. H. R. História e memória da educação indígena: um estudo do processo de escolarização dos WASSU - COCAL em Alagoas. Anais...VI Colóquio Internacional "Educação e Contemporaneidade", São Cristóvão-SE, set. 2014. Disponível em: <http://www.etnologiaindigena. blogspot.com/.../historia-e-memoria-da-educacao-indi>. Acesso em: 30 jun. 2015.

PLANO de Desenvolvimento Institucional da Ufopa (PDI 20122016). Disponível em: <http://www.ufopa.edu.br/arquivo/planodesenvolvimento-institucional-2012-2016>. Acesso em: 20 jan. 2016.

SANTOS, S. K. Política públicas educacionais no Brasil: tecendo fios. Anais... UFRGS, 2011. Disponível em: <http://www.anpae.org.br/ simposio2011/cdrom2011/PDFs/.../0271.pdf>. Acesso em: 08 jun. 2015.

SECCHI, D. Autonomia e protagonismo indígena nas políticas públicas. In: JANUÁRIO, E.; SILVA, F. S.; KARIM, T. M. (orgs.). Cadernos de Educação Escolar Indígena, v. 5, n. 1, 2007. Disponível em: <http://indigena. unemat.br>. Acesso em: 20 jun. 2015 